\title{
Peripheral blood transcriptomic sub-phenotypes of pediatric acute respiratory distress syndrome
}

Nadir Yehya ${ }^{1,2^{*}}$ D, Brian M. Varisco ${ }^{3,4}$, Neal J. Thomas ${ }^{5}$, Hector R. Wong ${ }^{3,4}$, Jason D. Christie $6,7,8$ and Rui Feng ${ }^{9}$

\begin{abstract}
Background: Acute respiratory distress syndrome (ARDS) is heterogeneous and may be amenable to sub-phenotyping to improve enrichment for trials. We aimed to identify subtypes of pediatric ARDS based on whole blood transcriptomics.

Methods: This was a prospective observational study of children with ARDS at the Children's Hospital of Philadelphia (CHOP) between January 2018 and June 2019. We collected blood within $24 \mathrm{~h}$ of ARDS onset, generated expression profiles, and performed k-means clustering to identify sub-phenotypes. We tested the association between subphenotypes and PICU mortality and ventilator-free days at 28 days using multivariable logistic and competing risk regression, respectively.
\end{abstract}

Results: We enrolled 106 subjects, of whom 96 had usable samples. We identified 3 sub-phenotypes, dubbed CHOP ARDS Transcriptomic Subtypes (CATS) 1, 2, and 3. CATS-1 subjects $(n=31)$ demonstrated persistent hypoxemia, had 10 subjects (32\%) with immunocompromising conditions, and 32\% mortality. CATS-2 subjects $(n=29)$ had more immunocompromising diagnoses (48\%), rapidly resolving hypoxemia, and $24 \%$ mortality. CATS-3 subjects $(n=36)$ had the fewest comorbidities, also had rapidly resolving hypoxemia, and 8\% mortality. The CATS-3 subtype was associated with lower mortality (OR $0.18,95 \% \mathrm{Cl} 0.04-0.86$ ) and higher probability of extubation (subdistribution HR 2.39, 95\% Cl 1.32-4.32), relative to CATS-1 after adjustment for confounders.

Conclusions: We identified three sub-phenotypes of pediatric ARDS using whole blood transcriptomics. The subphenotypes had divergent clinical characteristics and prognoses. Further studies should validate these findings and investigate mechanisms underlying differences between sub-phenotypes.

Keywords: Children, ARDS, PARDS, Endotypes, Gene expression, Sub-phenotypes

\section{Introduction}

Acute respiratory distress syndrome (ARDS) is characterized by acute onset of bilateral pulmonary edema and hypoxemia not fully explained by cardiac dysfunction $[1,2]$. Primarily defined for adults, ARDS affects 45,000

\footnotetext{
*Correspondence: yehyan@email.chop.edu

${ }^{1}$ Department of Anesthesiology and Critical Care Medicine, 6040A Wood Building, Children's Hospital of Philadelphia, 3401 Civic Center Boulevard, Philadelphia, PA 19104, USA

Full list of author information is available at the end of the article
}

children in the United States annually [3], representing $10 \%$ of mechanically ventilated children in pediatric intensive care units (PICUs) [4], with a mortality rate of $20 \%$ in the United States and 30\% worldwide [5, 6]. There are no specific pharmacological therapies for adult or pediatric ARDS despite several trials, and supportive care with lung-protective ventilation [7] and fluid restriction [8] remains the mainstay of treatment.

ARDS is heterogeneous, with patients having distinct comorbidities and inciting etiologies. This heterogeneity has contributed to negative trial results, as therapies

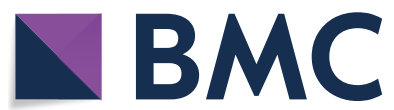

(c) The Author(s) 2020. This article is licensed under a Creative Commons Attribution 4.0 International License, which permits use, sharing, adaptation, distribution and reproduction in any medium or format, as long as you give appropriate credit to the original author(s) and the source, provide a link to the Creative Commons licence, and indicate if changes were made. The images or other third party material in this article are included in the article's Creative Commons licence, unless indicated otherwise in a credit line to the material. If material is not included in the article's Creative Commons licence and your intended use is not permitted by statutory regulation or exceeds the permitted use, you will need to obtain permission directly from the copyright holder. To view a copy of this licence, visit http://creativecommons.org/licenses/by/4.0/. The Creative Commons Public Domain Dedication waiver (http://creativecommons.org/publicdomain/zero/1.0/) applies to the data made available in this article, unless otherwise stated in a credit line to the data. 
effective in some patients are ineffective in others [9]. Methods to reduce heterogeneity, including sub-phenotyping using protein and mRNA biomarkers, have been proposed for improving patient selection for future clinical trials [10]. Extensive work in adult ARDS has demonstrated differential response to positive end-expiratory pressure [11], conservative fluid management [12], and simvastatin [13] depending on subtypes defined, in part, by protein biomarkers. By contrast, the presence of subtypes in pediatric ARDS is largely unexplored [14].

Whole blood transcriptomics has led to significant insights into the heterogeneity of adult $[15,16]$ and pediatric sepsis $[17,18]$. Unsupervised clustering has identified sepsis subtypes with differential biology, and potentially differential response to therapy [19]. Few gene expression studies have been performed in adult ARDS [20], and none in pediatrics. The aim of the present study was to identify sub-phenotypes of pediatric ARDS using unsupervised clustering on whole blood transcriptomics, hypothesizing that $\geq 2$ subtypes would be identified.

\section{Methods}

\section{Study design and subjects}

This was a prospective cohort study approved by the Children's Hospital of Philadelphia's (CHOP) Institutional Review Board between January 1, 2018 and June 30, 2019, with informed consent obtained prior to enrollment [21, 22 ]. Inclusion criteria were (1) acute ( $\leq 7$ days of risk factor) respiratory failure requiring invasive mechanical ventilation, (2) arterial access, (3) age $>1$ month and $<18$ years, (4) $\mathrm{PaO}_{2} / \mathrm{FIO}_{2} \leq 300$ on 2 consecutive arterial blood gases separated by $\geq 1 \mathrm{~h}$ on positive end-expiratory pressure (PEEP) $\geq 5 \mathrm{cmH}_{2} \mathrm{O}$, and (5) bilateral infiltrates on radiograph. Exclusion criteria were (1) respiratory failure from cardiac failure (by echocardiography), (2) exacerbation of underlying chronic lung disease, (3) chronic ventilator dependence, (4) cyanotic heart disease, (5) ventilation for $>7$ days before $\mathrm{PaO}_{2} / \mathrm{FIO}_{2} \leq 300$, (6) ARDS established outside of CHOP, (7) inability to obtain consent, or (8) prior enrollment.

\section{Procedures}

Clinical data were recorded prospectively. Blood was collected $\leq 24 \mathrm{~h}$ of ARDS onset (time of fulfilling all Berlin criteria) in PAXgene RNA tubes (BD Biosciences, San Jose, CA), kept overnight at room temperature up to $24 \mathrm{~h}$, and then stored at $-20{ }^{\circ} \mathrm{C}$ for batched analysis. After ensuring RNA integrity, we generated gene expression profiles using Human Gene 2.1 ST Array (Affymetrix, Santa Clara, CA) and the GeneTitan instrument. Microarray data was background-corrected and quantile-normalized using robust multi-array average for downstream analyses [23]. Data were uploaded to the Gene Expression Omnibus (GSE147902).

\section{Definitions}

Oxygenation index equaled: (mean airway pressure $\left.\times \mathrm{FIO}_{2} \times 100\right) / \mathrm{PaO}_{2}$ (in $\mathrm{mmHg}$ ). Vasopressor score [24] was: dopamine $(\mu \mathrm{g} / \mathrm{kg} / \mathrm{min}) \times 1+$ dobutamine $(\mu \mathrm{g} /$ $\mathrm{kg} / \mathrm{min}) \times 1+$ epinephrine $\quad(\mu \mathrm{g} / \mathrm{kg} / \mathrm{min}) \times 100+$ norepinephrine $(\mu \mathrm{g} / \mathrm{kg} / \mathrm{min}) \times 100+$ phenylephrine $(\mu \mathrm{g} / \mathrm{kg} /$ $\mathrm{min}) \times 100+$ milrinone $(\mu \mathrm{g} / \mathrm{kg} / \mathrm{min}) \times 10+$ vasopressin $(\mathrm{U} / \mathrm{kg} / \mathrm{min}) \times 10,000$. Severity of illness score was the Pediatric Risk of Mortality (PRISM) III at $12 \mathrm{~h}$. Non-pulmonary organ failures were defined using accepted definitions [25]. The designation of "immunocompromised" required presence of an immunocompromising diagnosis (oncologic, immunologic, rheumatologic, transplant) and active immunosuppressive therapy, or presence of a congenital immunodeficiency [26].

\section{Outcomes}

The objective of this study was to identify sub-phenotypes of pediatric ARDS and assess the association of these subtypes with clinical variables, PICU mortality, and ventilator-free days (VFDs) at 28 days. Only invasive ventilation was counted, with the first day as ARDS onset. Liberation from invasive ventilation for $>24 \mathrm{~h}$ defined ventilator duration. Patients requiring re-intubation $>24 \mathrm{~h}$ after extubation had additional days counted towards total ventilator days. VFDs were determined by subtracting total ventilator days from 28 in survivors. Patients with total ventilator days $\geq 28$ days and all PICU non-survivors were assigned VFD $=0$.

\section{Statistical analysis}

For sub-phenotype discovery, we analyzed gene expression using k-means clustering, restricting the analysis to 31,136 annotated genes (as of July 2019). We chose an optimal number of clusters $k$ using the gap statistic and 95\% confidence intervals (CI). First, we computed the gap statistic and $95 \% \mathrm{CI}$ for $k=1-10$, considering clusters with overlapping confidence intervals as having similar performance (Additional file 1: Fig. 1). We then chose the maximal gap statistic with $>10$ subjects per cluster ( $10 \%$ of entire cohort). Clustering was performed solely based on gene expression, blinded to clinical characteristics and outcomes. For pathway analysis of the identified sub-phenotypes, probes were filtered for expression values $\geq 10$ in $\geq 10$ samples and differentially expressed genes (DEGs) for each subtype determined using DESeq2 [27] with BioMaRT [28]. Two-fold upregulated and downregulated DEGs were analyzed in Ingenuity Pathway Analysis (IPA) [29] and ToppGene [30] to identify predicted upstream regulators, Gene Ontogeny terms, 
and key pathways. Pathways with $q$ value $<0.1$ are presented in the Supplement.

Sub-phenotypes were assessed for association with clinical characteristics using non-parametric statistics. Categorical data were compared using Fisher exact test. We tested the association between sub-phenotypes and mortality and VFDs using logistic and competing risk regression [31], respectively, adjusting for (individually and together) immunocompromised status and PRISM III score. We reasoned that these two variables plausibly contributed to both the identity of the sub-phenotypes as well as outcomes, as they are associated with circulating immune cell gene expression and pulmonary and non-pulmonary severity of illness. Thus, immunocompromised status and PRISM III represent potential confounding of the association between subtypes and outcomes. Separately, we tested the association between sub-phenotypes and outcome adjusting for predicted mortality based on a recent pediatric ARDS-specific mortality prediction score [32]. Additionally, we repeated the above regressions while also adjusting for absolute neutrophil count (ANC) and absolute lymphocyte count (ALC) in order to assess whether associations between sub-phenotypes and outcomes were driven by lymphocyte subset proportions. Due to the limited number of deaths in the cohort, we restricted the number of confounders in all models to minimize bias and variance. Analyses were performed in Stata 14.2/SE (StataCorp, LP, College Station, TX) and R 3.0.1 (www.r-project.org). Heatmaps were generated with pheatmap and gridExtra in R.

\section{Results}

Between January 2018 and June 2019, 140 children had ARDS. We consented and enrolled 106 subjects (76\%), of whom 96 had usable samples (excluded 8 for low RNA yield due to leukopenia, and 2 for poor quality RNA). Of these 96 subjects, 20 (21\%) were non-survivors. Considering cluster gap statistic, 95\% CI overlap and cluster size, $k=3$ was chosen (Fig. 1 ). Sub-phenotypes were designated CHOP ARDS Transcriptomic Subtypes (CATS) 1,2 , and 3 , and did not differ in severity of illness, ARDS

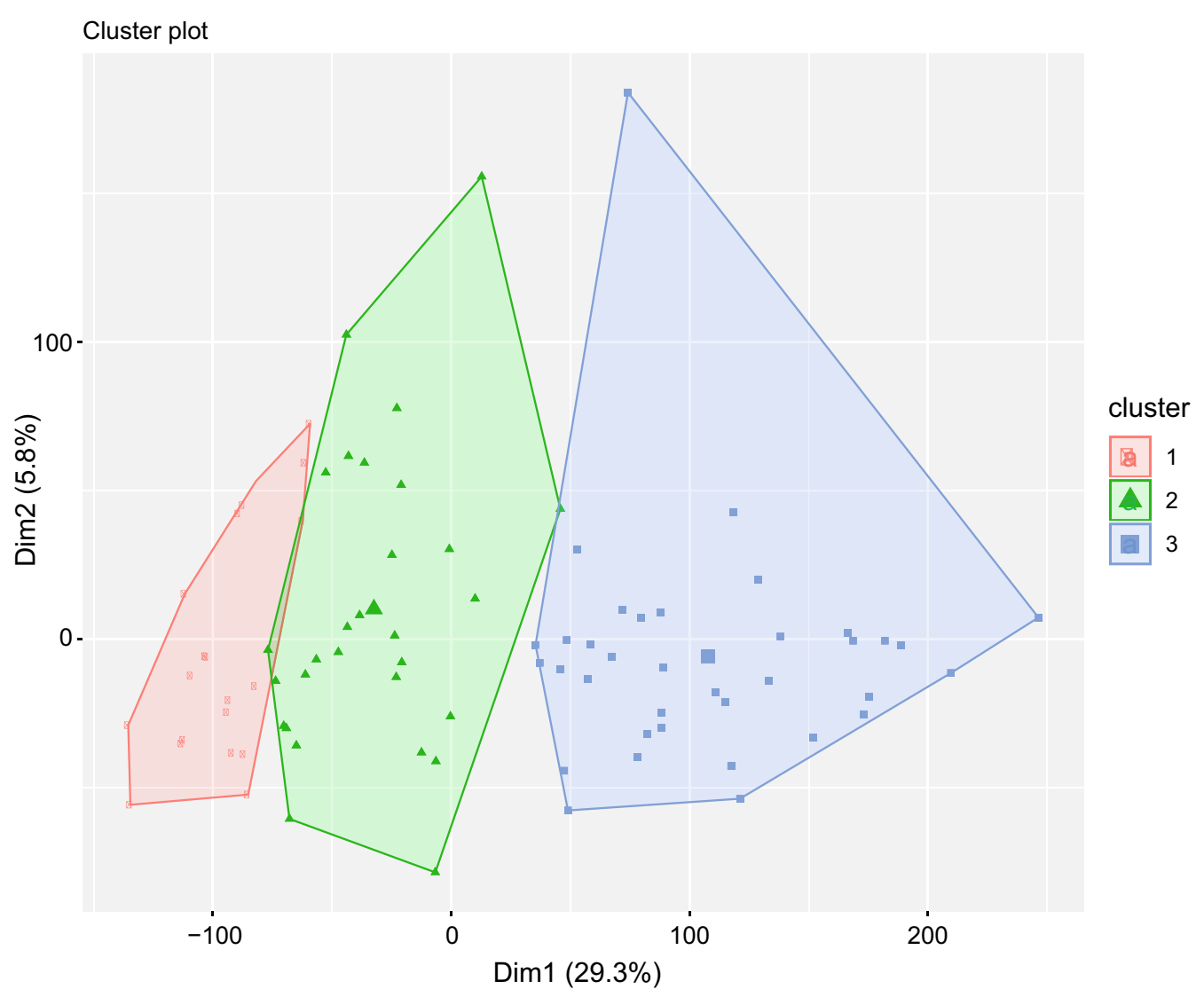

Fig. 1 Three clusters identified using unsupervised k-means clustering, dubbed CHOP ARDS Transcriptomic Subtypes (CATS) 1 (red), 2 (green), and 3 (blue). The individual subjects are plotted in a 2-dimensional plot, with the principle dimensions (Dim 1 and 2) which account for $29.3 \%$ and $5.8 \%$ of the variance, as the axes 
etiology, or ARDS severity at onset (Table 1). Sub-phenotypes differed by proportion of immunocompromised subjects, with CATS-1 (32\%) and CATS-2 (48\%) having more immunocompromised subjects, relative to CATS-3 $(14 \% ; p=0.011)$. CATS-1 had worse hypoxemia at $24 \mathrm{~h}$, relative to the other subtypes.

To understand the biology of the sub-phenotypes, we analyzed the association between sub-phenotype and total leukocytes, ANC, and ALC (Additional file 1: Table 1). All leukocyte metrics were associated with CATS subtypes, with modest overall effect sizes $\left(\eta^{2}\right)$ between 5.4 and $11.2 \%$. We performed analyses assessing for upstream regulators, Gene Ontogeny terms, and key pathways (Fig. 2; Additional file 1: Figs. 2-7).
CATS-1 was enriched for adaptive immune and $\mathrm{T}$ cell pathways. CATS-2 was enriched for complement pathways. CATS-3 showed upregulation of G-protein receptor signaling and olfactory pathways. Regulator analysis demonstrated significant inflammatory cytokine regulation of CATS-1 pathways.

In unadjusted analysis, CATS-3 had better survival and more VFDs than the other subtypes (Table 1, Fig. 3). After adjustment for PRISM III and immunocompromised status (Table 2), CATS-3 remained associated with lower mortality (OR $0.18,95 \%$ CI $0.04-0.86$ ) and higher probability of extubation (subdistribution HR 2.39, 95\% CI 1.32-4.32). Adjustment for PRISM III strengthened this association, whereas adjustment for

Table 1 Demographics stratified by CHOP ARDS Transcriptomic Subtypes (CATS)

\begin{tabular}{|c|c|c|c|c|}
\hline Variables & CATS- $1(n=31)$ & CATS-2 $(n=29)$ & CATS-3 $(n=36)$ & $p$ value \\
\hline Age (years) & $6.8[1.2,13]$ & $14.1[6.9,16.5]$ & $7[1.8,12.8]$ & 0.006 \\
\hline Female (\%) & $13(42)$ & $12(42)$ & $13(36)$ & 0.898 \\
\hline \multicolumn{5}{|l|}{ Severity of illness } \\
\hline PRISM III at $12 \mathrm{~h}$ & $9[5,15]$ & $13[8,18]$ & $12[7,21]$ & 0.278 \\
\hline Non-pulmonary organ failures & $2[1,3]$ & $1[1,2]$ & $1[1,2]$ & 0.530 \\
\hline Vasopressor score & $10[4,18]$ & $5[0,12]$ & $7[0,28]$ & 0.313 \\
\hline \multicolumn{5}{|l|}{ Co-morbidities (\%) } \\
\hline Immunocompromised & $10(32)$ & $14(48)$ & $5(14)$ & 0.011 \\
\hline Stem cell transplant & $4(13)$ & $8(28)$ & $2(6)$ & 0.040 \\
\hline \multicolumn{5}{|l|}{ Cause of ARDS (\%) } \\
\hline Direct & $22(71)$ & $23(79)$ & $25(69)$ & 0.652 \\
\hline Indirect & $9(29)$ & $6(21)$ & $11(31)$ & \\
\hline \multicolumn{5}{|l|}{ Cause of ARDS (\%) } \\
\hline Infectious & $21(68)$ & $25(86)$ & $29(81)$ & 0.211 \\
\hline Non-infectious & $10(32)$ & $4(14)$ & $7(19)$ & \\
\hline \multicolumn{5}{|l|}{ Cause of ARDS (\%) } \\
\hline Infectious pneumonia & $16(52)$ & $19(66)$ & $21(58)$ & \\
\hline Non-pulmonary sepsis & $5(16)$ & $6(21)$ & $8(22)$ & \\
\hline Aspiration pneumonia & $4(13)$ & $3(10)$ & $3(8)$ & 0.606 \\
\hline Trauma & $1(3)$ & $1(3)$ & $1(3)$ & \\
\hline Other & $5(16)$ & 0 & $3(8)$ & \\
\hline \multicolumn{5}{|l|}{ ARDS onset } \\
\hline $\mathrm{PaO}_{2} / \mathrm{FlO}_{2}$ & $152[88,243]$ & $148[121,222]$ & $138[85,187]$ & 0.450 \\
\hline $\mathrm{Ol}$ & $11.1[6.7,18.1]$ & $11[8.7,13.4]$ & $13.5[9.6,23.9]$ & 0.371 \\
\hline \multicolumn{5}{|l|}{$24 \mathrm{~h}$ after onset } \\
\hline $\mathrm{PaO}_{2} / \mathrm{FIO}_{2}$ & $179[130,240]$ & $236[182,292]$ & $252[186,323]$ & 0.002 \\
\hline $\mathrm{Ol}$ & $9.8[6.2,14.3]$ & $5.7[4.8,8.1]$ & $6[4.3,10.6]$ & 0.004 \\
\hline \multicolumn{5}{|l|}{ Outcomes } \\
\hline Ventilator days (all) & $7[5,12]$ & $10[5,24]$ & $6[4,10]$ & 0.152 \\
\hline Ventilator days (survivors) & $7[6,12]$ & $9[5,16]$ & $6[4,10]$ & 0.201 \\
\hline VFDs at 28 days & $16[0,22]$ & $16[0,21]$ & $22[12,24]$ & 0.012 \\
\hline PICU mortality (\%) & $10(32)$ & $7(24)$ & $3(8)$ & 0.039 \\
\hline
\end{tabular}


a

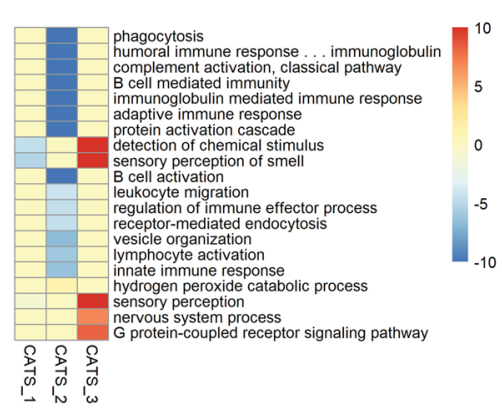

b
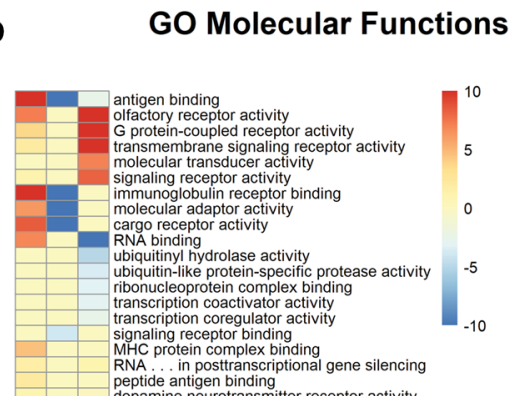

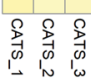

C

\section{Pathways}

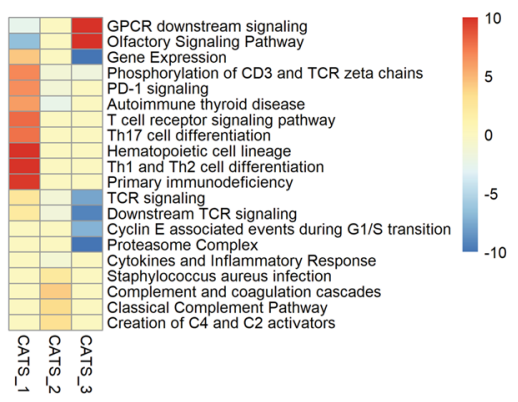

d Gene Families

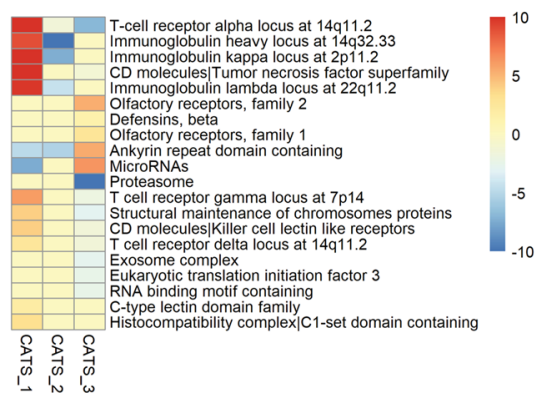

e

IPA Upstream Regulators

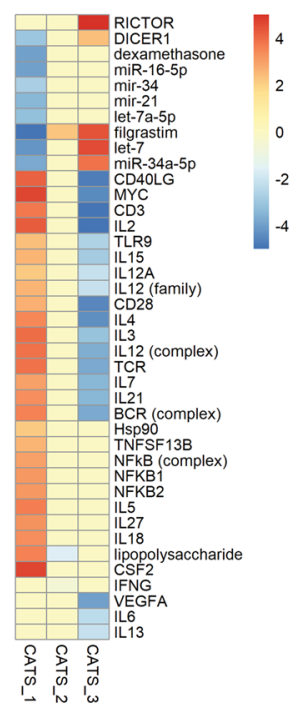

f IPA Master Regulators

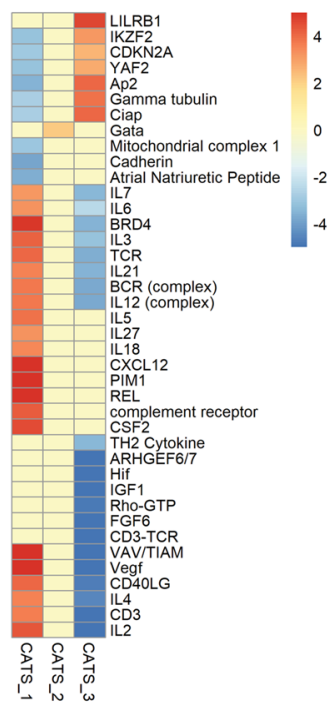

Fig. 2 Heatmap of over- and under-expressed functional pathways and regulators using Gene Ontology (GO) and Ingenuity Pathway Analysis (IPA). The scale for A to D represents - $\log _{10}\left(q\right.$ value) for upregulated and $\log _{10}(q$ value) for downregulated terms. Color scale represents activation/ inhibition score for $\mathrm{E}$ and $\mathrm{F}$ 


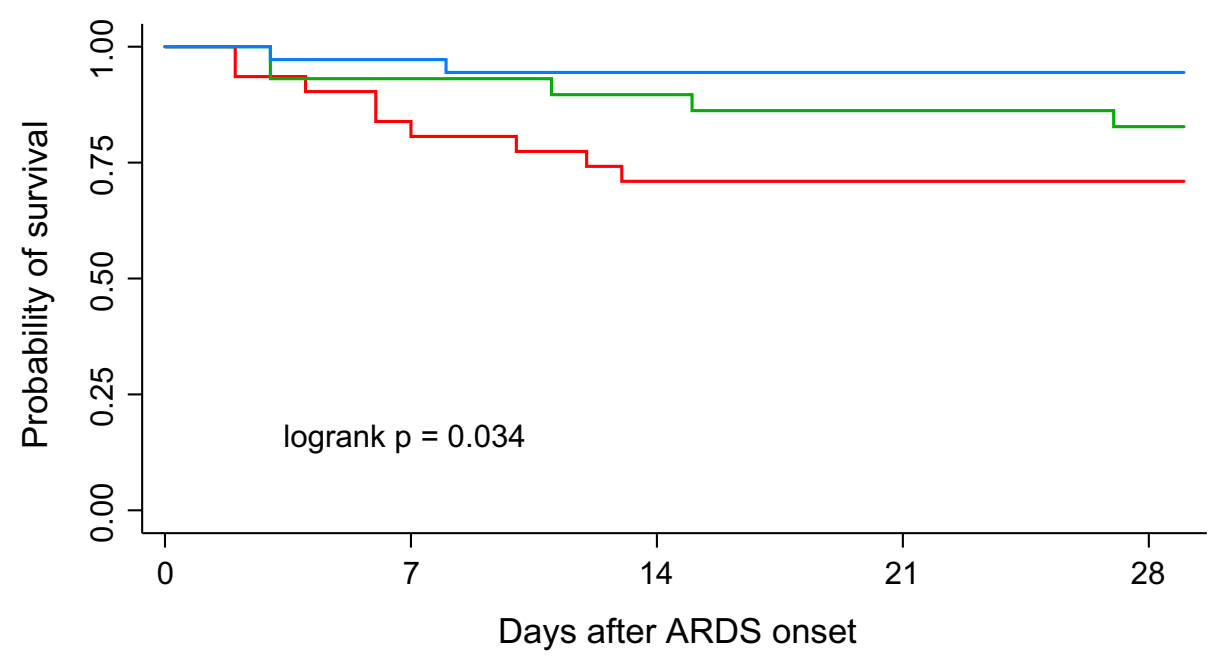

Number at risk

CATS-1 31

CATS-2 29

CATS-3 36

26

27

35
22

26

34
22

25

34

CATS-2

\section{CATS-1}

CATS-3

Fig. 3 Kaplan-Meier survival curves for the CHOP ARDS Transcriptomic Subtypes (CATS); overall log-rank is significant $(p=0.034)$; in pairwise comparisons, the comparison between CATS- 1 and CATS-3 reached statistical significance $(p=0.010)$

immunocompromised status attenuated it. Results were unchanged when also adjusting for ANC or ALC. We found similar results when we adjusted for the probability of death based on a published prediction model (Additional file 1: Table 2). The association of CATS-3 with better outcomes was not completely explained by fewer immunocompromised subjects in CATS-3, as an analysis restricted to immunocompetent subjects had point estimates confirming the association with lower mortality and greater VFDs in CATS-3 (Additional file 1: Table 3), although not all analyses reached statistical significance with the reduced sample size.

\section{Discussion}

We identified three sub-phenotypes of pediatric ARDS with distinct biologic pathways and prognoses using whole blood transcriptomics within $24 \mathrm{~h}$ of ARDS onset. The sub-phenotypes demonstrated some overlap of traditional clinical characteristics of ARDS severity, with immunocompromised status, stem cell transplant, and severe hypoxemia seen at differing proportions across all subtypes. Transcriptomic sub-phenotypes may provide insight into molecular mechanisms underlying pediatric ARDS heterogeneity, particularly when combined with clinical characteristics.
ARDS heterogeneity has contributed to the paucity of therapies, and sub-classification into subtypes has been proposed as a way to address this. ARDS has been divided into direct or indirect [33-35], infectious or non-infectious [36, 37], focal versus non-focal [38], and on the basis of biomarkers $[11,33]$. A recent trial attempted predictive enrichment by stratifying treatment arm based on radiographic classification of focal or non-focal ARDS [39]. A limitation of this approach in this trial was the imprecision of the clinical designation of focal versus non-focal ARDS, with $21 \%$ of subjects misclassified. Thus, while clinical variables such as risk factors and comorbidities can inform heterogeneity, these terms remain imprecise.

Biomarker- and transcriptomic-based sub-phenotyping may offer some advantages, including greater insight into pathophysiology. Re-analysis of adult ARDS trials have identified hyper- and hypo-inflammatory sub-phenotypes characterized, in part, by differential levels of inflammatory biomarkers [11-13] and gene expression [40]. These findings in adults, and our results in pediatrics, demonstrate the utility of transcriptomics to uncover mechanisms underlying subtypes. Indeed, transcriptomics offer higher dimensional analysis, relative to protein biomarkers, a fact 
Table 2 Logistic regression and competing risk regression assessing association of CHOP ARDS Transcriptomic Subtypes (CATS) clusters and PICU mortality or probability of extubation by day 28 (accounting for the competing risk of death)

\begin{tabular}{|c|c|c|c|c|}
\hline & \multicolumn{2}{|l|}{ PICU mortality } & \multicolumn{2}{|l|}{$\begin{array}{l}\text { Probability } \\
\text { of extubation }\end{array}$} \\
\hline & OR $(95 \% \mathrm{Cl})^{\mathrm{a}}$ & $p$ value & SHR $(95 \% \mathrm{CI})^{\mathbf{b}}$ & $p$ value \\
\hline \multicolumn{5}{|c|}{ Unadjusted } \\
\hline CATS-1 & Ref & - & Ref & - \\
\hline CATS-2 & $0.67(0.21-2.08)$ & 0.487 & $1.01(0.54-1.91)$ & 0.967 \\
\hline CATS-3 & $0.19(0.05-0.78)$ & 0.021 & $2.15(1.26-3.64)$ & 0.005 \\
\hline \multicolumn{5}{|c|}{ Adjusted for PRISM III } \\
\hline CATS-1 & Ref & - & Ref & - \\
\hline CATS-2 & $0.53(0.16-1.76)$ & 0.300 & $1.14(0.60-2.17)$ & 0.686 \\
\hline CATS-3 & $0.13(0.03-0.60)$ & 0.009 & $2.83(1.55-5.17)$ & 0.001 \\
\hline \multicolumn{5}{|c|}{ Adjusted for immunocompromised } \\
\hline CATS-1 & Ref & - & Ref & - \\
\hline CATS-2 & $0.44(0.12-1.58)$ & 0.207 & $1.20(0.66-2.18)$ & 0.557 \\
\hline CATS-3 & $0.24(0.06-1.07)$ & 0.061 & $1.74(1.02-3.00)$ & 0.044 \\
\hline \multicolumn{5}{|c|}{$\begin{array}{l}\text { Adjusted } \\
\text { for PRISM } \\
\text { III+ immuno- } \\
\text { compromised }\end{array}$} \\
\hline CATS-1 & Ref & - & Ref & - \\
\hline CATS-2 & $0.35(0.09-1.36)$ & 0.130 & $1.35(0.74-2.44)$ & 0.329 \\
\hline CATS-3 & $0.18(0.04-0.86)$ & 0.031 & $2.39(1.32-4.32)$ & 0.004 \\
\hline \multicolumn{5}{|c|}{ Adjusted for PRISM + immunocompromised + ANC } \\
\hline CATS-1 & Ref & - & Ref & - \\
\hline CATS-2 & $0.28(0.07-1.14)$ & 0.074 & $1.44(0.78-2.67)$ & 0.247 \\
\hline CATS-3 & $0.11(0.02-0.60)$ & 0.011 & $2.77(1.38-5.57)$ & 0.004 \\
\hline \multicolumn{5}{|c|}{ Adjusted for PRISM + immunocompromised + ALC } \\
\hline CATS-1 & Ref & - & Ref & - \\
\hline CATS-2 & $0.42(0.10-1.67)$ & 0.221 & $1.25(0.69-2.27)$ & 0.456 \\
\hline CATS-3 & $0.19(0.04-0.90)$ & 0.036 & $2.37(1.32-4.25)$ & 0.004 \\
\hline
\end{tabular}

$A L C$ absolute lymphocyte count, $A N C$ absolute neutrophil count, PRISM III Pediatric Risk of Mortality III

a Odds ratio $(O R)<1$ : lower odds of mortality

b Subdistribution hazard ratio (SHR) > 1: greater hazard for extubation alive (i.e., shorter duration of ventilation)

which potentially allows for better discrimination of sub-phenotypes.

We have previously demonstrated that infectious and non-infectious ARDS have different predictors of mortality [37]. CATS sub-phenotypes did not stratify according to either direct/indirect or infectious/non-infectious classifications. This may reflect the imprecision of clinical subtyping, different underlying biology between clinical characterization and peripheral gene expression, or low power. However, clinical characteristics may potentially serve as one level of sub-classification which can be improved upon with the addition of transcriptomics. Full realization of this requires more rapid turnaround for biologic-based sub-phenotyping, as clinical categorization is immediately applicable at bedside.

CATS sub-phenotypes revealed mechanisms which were not immediately apparent. CATS-1, for example, was enriched in adaptive immunity, which could be related to its relatively higher ALC. CATS-1 also demonstrated persistent hypoxemia, which is potentially related to signaling associated with adaptive immunity or to the types of organisms which may have caused the ARDS. CATS-2, which had nearly half of its subjects immunocompromised, was enriched in complement-related pathways, consistent with an emerging role for this pathway with stem cell transplant patients [41]. CATS-3 had suppression of adaptive immune and $\mathrm{T}$ cell receptor pathways. The sub-phenotypes also demonstrated prognostic utility, with CATS-3 subjects demonstrating improved survival and VFDs in unadjusted and adjusted analyses.

There are few trials in pediatric ARDS, and management is largely extrapolated from adults. The identification of sub-phenotypes with divergent biology forms the premise for targeted treatment. Subtypes with differential upregulation of innate and adaptive immunity offer intriguing opportunities for predictive enrichment in future trials of immunomodulatory therapies. Transcriptomics also allows insight into the mechanisms underlying the broader condition of ARDS, as well as the pathophysiology underlying different subtypes. ARDS has long been considered a disease of predominantly neutrophil infiltration [42, 43]. However, leukocyte populations and pathways other than innate immune hyperinflammation contribute to ARDS pathogenesis, which can potentially be dissected via transcriptomics $[44,45]$.

Given the ARDS heterogeneity, transcriptomic differences between the CATS sub-phenotypes may simply reflect differences in underlying risk factors, limiting their utility for predictive enrichment. However, the molecular basis for the heterogeneity of risk factors is also poorly elucidated. Pathway enrichment of the CATS sub-phenotypes provides insights into the different immune pathways implicated in early ARDS. Whether this can assist with predictive enrichment remains to be demonstrated. However, given the differences in mortality rate, these sub-phenotypes may also have a role for prognostic enrichment.

We performed microarray rather than direct RNA sequencing (RNA-seq). While RNA-seq provides greater dynamic range and is superior at identifying low abundance transcripts, whole blood presents unique challenges. Up to $70 \%$ of the mRNA in a blood total RNA sample can be globin mRNA, with the remaining total RNA composed of $>90 \%$ ribosomal RNA 
(rRNA). Neither globin mRNA nor rRNA sequences contribute high-value information, and unlike hybridization techniques, over-representation of non-informative sequences consume reagents and require greater sequencing depth to yield useful information. Globinand rRNA-depletion techniques are available [46, 47]; however, depletion techniques reduce the amount of RNA (particularly from leukopenic subjects) and potentially introduce artifact. Since microarrays are based on hybridization, over-abundance of globin or rRNA is less problematic, and so microarray was chosen for this study. Notably, every whole blood transcriptomic sub-phenotyping study to date has used microarray [15, 16, 48]. However, as RNA-seq technology improves and achieves better performance in whole blood, future transcriptomic studies may benefit from the improved coverage of direct sequencing technologies.

Our study has several strengths. We prospectively collected blood $\leq 24 \mathrm{~h}$ of ARDS onset and generated expression profiles in $>90 \%$ of samples. Detailed clinical data was collected and correlated with sub-phenotypes. However, our study has important limitations. Subjects were recruited from a single center, which may limit generalizability. However, demographics and severity of ARDS are comparable to other published cohorts [6, 49-51]. We did not use the recent Pediatric Acute Lung Injury Consensus Conference (PALICC) definition of pediatric ARDS [52], which allows unilateral infiltrates and has a specific $\mathrm{SpO}_{2}$-based severity stratification. Cohorts defined using PALICC may differ from ours in important ways which limit generalizability. Our sample size was small and only collected at ARDS onset, limiting our ability to fully characterize the subtypes, assess their temporal stability, and detect associations with outcomes. Our small sample size and low mortality rate precluded adjustment for multiple potential confounders. We sampled the blood, which while accessible, may not best reflect the transcriptome most relevant for ARDS. Alveolar sampling is uncommon in pediatrics, and impractical for most clinical trial purposes. A future goal will be to reduce the number of transcripts required to discriminate between sub-phenotypes and operationalize a subtyping strategy. We did not include an external control population to assess upor down-regulation of pathways, relative to a non-ARDS cohort. Most importantly, our study lacks a validation cohort to assess the robustness of the CATS sub-phenotypes. This is the first transcriptomic study of pediatric ARDS, and validation cohorts with mRNA collection are lacking. Future studies of pediatric ARDS with transcriptomics are needed to assess for reproducibility of the CATS sub-phenotypes. Development of a reduced gene signature would simplify this process, and is the focus of current work. Future cohorts should have parallel efforts correlating transcriptomics with plasma biomarkers, as a protein biomarker-based signature would likely prove faster, cheaper, and less labor-intensive. Biomarkers could also delineate mechanisms underlying the subphenotypes, as well as facilitate comparisons with adult sub-phenotypes which have largely been defined using plasma proteins [11-13]. Re-analyses of adult ARDS trials have suggested differential treatment response based on subtype. To reproduce this in children, future trials in pediatric ARDS should collect both plasma for proteins and whole blood mRNA for transcriptomics and test treatment response by sub-phenotypes, as differences between adult and pediatric ARDS do not necessarily allow for translation of adult trial data to children.

\section{Conclusions}

We identified three sub-phenotypes of pediatric ARDS using whole blood transcriptomics. The subtypes had differing clinical characteristics and divergent prognoses. Further studies should validate these findings and investigate mechanisms underlying differences between sub-phenotypes. Our results are the first steps towards reducing heterogeneity and designing trials of targeted, precision therapies in pediatric ARDS.

\section{Supplementary information}

Supplementary information accompanies this paper at https://doi. org/10.1186/s13054-020-03410-7.

Additional file 1.

\section{Abbreviations}

ALC: Absolute lymphocyte count; ANC: Absolute neutrophil count; ARDS: Acute respiratory distress syndrome; CATS: CHOP ARDS Transcriptomic Subtypes; CHOP: Children's Hospital of Philadelphia; DEGs: Differentially expressed genes; IPA: Ingenuity Pathway Analysis; Ol: Oxygenation index; PEEP: Positive end-expiratory pressure; PICU: Pediatric intensive care unit; PRISM: Pediatric Risk of Mortality; RNA: Ribonucleic acid; VFDs: Ventilator-free days.

\section{Authors' contributions}

NY, NJT, and HRW conceived and designed the study. NY, BMV, and RF performed data analysis. JDC provided important intellectual content to the project. NY wrote the initial version, and all authors edited, contributed, and approved the final version of this manuscript. All authors read and approved the final manuscript.

\section{Funding}

K23-HL136688 (NY); R01-HL148054 (NY); R01-HL141229 (BMV); R35-GM126943 (HRW); K24-HL115354 (JDC)

\section{Availability of data and materials}

The clinical datasets used and/or analyzed during the current study are available from the corresponding author on reasonable request. Microarray data are available in the Gene Expression Omnibus (GSE147902).

\section{Ethics approval and consent to participate}

The study was approved by the Children's Hospital of Philadelphia Institutional Review Board (13-010578) and informed consent was obtained for each subject. 


\section{Consent for publication}

Not applicable.

\section{Competing interests}

JDC reports grants from GlaxoSmithKline, Bristol-Meyers Squibb, and personal fees from Onspira and Magnolia, all outside the submitted work.

\section{Author details}

${ }^{1}$ Department of Anesthesiology and Critical Care Medicine, 6040A Wood Building, Children's Hospital of Philadelphia, 3401 Civic Center Boulevard, Philadelphia, PA 19104, USA. ${ }^{2}$ University of Pennsylvania, Philadelphia, PA, USA. ${ }^{3}$ Division of Critical Care Medicine, Department of Pediatrics, Cincinnati Children's Hospital Medical Center, Cincinnati, OH, USA. ${ }^{4}$ College of Medicine, University of Cincinnati, Cincinnati, OH, USA. ${ }^{5}$ Division of Pediatric Critical Care Medicine, Department of Pediatrics and Public Health Science, Penn State Hershey Children's Hospital, Hershey, PA, USA. ${ }^{6}$ Critical Care Division, Department of Medicine, Pulmonary, Allergy, Perelman School of Medicine, University of Pennsylvania, Philadelphia, PA, USA. ${ }^{7}$ Center for Translational Lung Biology, Perelman School of Medicine, University of Pennsylvania, Philadelphia, PA, USA. ${ }^{8}$ Center for Clinical Epidemiology and Biostatistics, Perelman School of Medicine, University of Pennsylvania, Philadelphia, PA, USA. ${ }^{9}$ Department of Biostatistics, Center for Clinical Epidemiology and Biostatistics, Epidemiology, and Informatics, University of Pennsylvania, Philadelphia, PA, USA.

\section{Received: 31 August 2020 Accepted: 24 November 2020}

Published online: 07 December 2020

\section{References}

1. Bernard GR, Artigas A, Brigham KL, Carlet J, Falke K, Hudson L, Lamy M, Legall JR, Morris A, Spragg R. The American-European Consensus Conference on ARDS. Definitions, mechanisms, relevant outcomes, and clinical trial coordination. Am J Respir Crit Care Med. 1994;149(3):818-24.

2. Force ADT, Ranieri VM, Rubenfeld GD, Thompson BT, Ferguson ND, Caldwell E, Fan E, Camporota L, Slutsky AS. Acute respiratory distress syndrome: the Berlin Definition. JAMA. 2012;307(23):2526-33.

3. Zimmerman JJ, Akhtar SR, Caldwell E, Rubenfeld GD. Incidence and outcomes of pediatric acute lung injury. Pediatrics. 2009;124(1):87-95.

4. Yehya N, Servaes S, Thomas NJ. Characterizing degree of lung injury in pediatric acute respiratory distress syndrome. Crit Care Med. 2015;43(5):937-46.

5. Schouten LR, Veltkamp F, Bos AP, van Woensel JB, Serpa Neto A, Schultz MJ, Wosten-van Asperen RM. Incidence and mortality of acute respiratory distress syndrome in children: a systematic review and meta-analysis. Crit Care Med. 2016;44(4):819-29.

6. Khemani RG, Smith L, Lopez-Fernandez YM, Kwok J, Morzov R, Klein MJ, Yehya N, Willson D, Kneyber MCJ, Lillie J, et al. Paediatric acute respiratory distress syndrome incidence and epidemiology (PARDIE): an international, observational study. Lancet Respir Med. 2019;7(2):115-28.

7. Acute Respiratory Distress Syndrome Network, Brower RG, Matthay MA, Morris A, Schoenfeld D, Thompson BT, Wheeler A. Ventilation with lower tidal volumes as compared with traditional tidal volumes for acute lung injury and the acute respiratory distress syndrome. N Engl J Med. 2000;342(18):1301-8.

8. National Heart, Lung, and Blood Institute Acute Respiratory Distress Syndrome (ARDS) Clinical Trials Network, Wiedemann HP, Wheeler AP, Bernard GR, Thompson BT, Hayden D, deBoisblanc B, Connors AF Jr, Hite $\mathrm{RD}$, et al. Comparison of two fluid-management strategies in acute lung injury. N Engl J Med. 2006;354(24):2564-75.

9. Iwashyna TJ, Burke JF, Sussman JB, Prescott HC, Hayward RA, Angus DC. Implications of heterogeneity of treatment effect for reporting and analysis of randomized trials in critical care. Am J Respir Crit Care Med. 2015;192(9):1045-51.

10. Prescott HC, Calfee CS, Thompson BT, Angus DC, Liu VX. Toward smarter lumping and smarter splitting: rethinking strategies for sepsis and acute respiratory distress syndrome clinical trial design. Am J Respir Crit Care Med. 2016;194(2):147-55.

11. Calfee CS, Delucchi K, Parsons PE, Thompson BT, Ware LB, Matthay MA, Network NA. Subphenotypes in acute respiratory distress syndrome: latent class analysis of data from two randomised controlled trials. Lancet Respir Med. 2014;2(8):611-20.

12. Famous KR, Delucchi K, Ware LB, Kangelaris KN, Liu KD, Thompson BT, Calfee CS, Network A. Acute respiratory distress syndrome subphenotypes respond differently to randomized fluid management strategy. Am J Respir Crit Care Med. 2017;195(3):331-8.

13. Calfee CS, Delucchi KL, Sinha P, Matthay MA, Hackett J, Shankar-Hari M, McDowell C, Laffey JG, O'Kane CM, McAuley DF, et al. Acute respiratory distress syndrome subphenotypes and differential response to simvastatin: secondary analysis of a randomised controlled trial. Lancet Respir Med. 2018;6(9):691-8.

14. Zinter MS, Delucchi KL, Kong MY, Orwoll BE, Spicer AS, Lim MJ, Alkhouli MF, Ratiu AE, McKenzie AV, McQuillen PS, et al. Early plasma matrix metalloproteinase profiles. A novel pathway in pediatric acute respiratory distress syndrome. Am J Respir Crit Care Med. 2019;199(2):181-9.

15. Scicluna BP, van Vught LA, Zwinderman AH, Wiewel MA, Davenport EE, Burnham KL, Nurnberg P, Schultz MJ, Horn J, Cremer OL, et al. Classification of patients with sepsis according to blood genomic endotype: a prospective cohort study. Lancet Respir Med. 2017;5(10):816-26.

16. Sweeney TE, Perumal TM, Henao R, Nichols M, Howrylak JA, Choi AM, Bermejo-Martin JF, Almansa R, Tamayo E, Davenport EE, et al. A community approach to mortality prediction in sepsis via gene expression analysis. Nat Commun. 2018;9(1):694.

17. Wong HR, Cvijanovich NZ, Allen GL, Thomas NJ, Freishtat RJ, Anas N, Meyer K, Checchia PA, Weiss SL, Shanley TP, et al. Corticosteroids are associated with repression of adaptive immunity gene programs in pediatric septic shock. Am J Respir Crit Care Med. 2014;189(8):940-6.

18. Wong HR, Cvijanovich NZ, Anas N, Allen GL, Thomas NJ, Bigham MT, Weiss SL, Fitzgerald JC, Checchia PA, Meyer K, et al. Improved risk stratification in pediatric septic shock using both protein and mRNA biomarkers. PERSEVERE-XP. Am J Respir Crit Care Med. 2017;196(4):494-501.

19. Wong HR, Atkinson SJ, Cvijanovich NZ, Anas N, Allen GL, Thomas NJ, Bigham MT, Weiss SL, Fitzgerald JC, Checchia PA, et al. Combining prognostic and predictive enrichment strategies to identify children with septic shock responsive to corticosteroids. Crit Care Med. 2016:44(10):e1000-1003.

20. Kangelaris KN, Prakash A, Liu KD, Aouizerat B, Woodruff PG, Erle DJ, Rogers A, Seeley EJ, Chu J, Liu T, et al. Increased expression of neutrophil-related genes in patients with early sepsis-induced ARDS. Am J Physiol Lung Cell Mol Physiol. 2015;308(11):L1102-1113.

21. Yehya N, Thomas NJ, Margulies SS. Circulating nucleosomes are associated with mortality in pediatric acute respiratory distress syndrome. Am J Physiol Lung Cell Mol Physiol. 2016;310(11):L1177-1184.

22. Yehya N, Thomas NJ, Meyer NJ, Christie JD, Berg RA, Margulies SS. Circulating markers of endothelial and alveolar epithelial dysfunction are associated with mortality in pediatric acute respiratory distress syndrome. Intensive Care Med. 2016:42(7):1137-45.

23. Irizarry RA, Hobbs B, Collin F, Beazer-Barclay YD, Antonellis KJ, Scherf U, Speed TP. Exploration, normalization, and summaries of high density oligonucleotide array probe level data. Biostatistics. 2003;4(2):249-64.

24. Gaies MG, Gurney JG, Yen AH, Napoli ML, Gajarski RJ, Ohye RG, Charpie $J R$, Hirsch JC. Vasoactive-inotropic score as a predictor of morbidity and mortality in infants after cardiopulmonary bypass. Pediatr Crit Care Med. 2010;11(2):234-8.

25. Goldstein B, Giroir B, Randolph A, International Consensus Conference on Pediatric Sepsis. International pediatric sepsis consensus conference: definitions for sepsis and organ dysfunction in pediatrics. Pediatr Crit Care Med. 2005:6(1):2-8.

26. Yehya N, Topjian AA, Thomas NJ, Friess SH. Improved oxygenation 24 hours after transition to airway pressure release ventilation or highfrequency oscillatory ventilation accurately discriminates survival in immunocompromised pediatric patients with acute respiratory distress syndrome. Pediatr Crit Care Med. 2014;15(4):e147-156.

27. Love MI, Huber W, Anders S, Paediatric Study GroupPaediatric Study Group, Australian and New Zealand Intensive Care Society. Moderated estimation of fold change and dispersion for RNA-seq data with DESeq2. Genome Biol. 2014;15(12):550.

28. Durinck S, Moreau Y, Kasprzyk A, Davis S, De Moor B, Brazma A, Huber W. BioMart and Bioconductor: a powerful link between biological databases and microarray data analysis. Bioinformatics. 2005;21(16):3439-40. 
29. Kramer A, Green J, Pollard J Jr, Tugendreich S. Causal analysis approaches in Ingenuity Pathway Analysis. Bioinformatics. 2014;30(4):523-30.

30. Chen J, Bardes EE, Aronow BJ, Jegga AG. ToppGene Suite for gene list enrichment analysis and candidate gene prioritization. Nucleic Acids Res. 2009;37(Web Server issue):W305-311.

31. Yehya N, Harhay MO, Curley MAQ, Schoenfeld DA, Reeder RW. Reappraisal of ventilator-free days in critical care research. Am J Respir Crit Care Med. 2019;200(7):828-36.

32. Yehya N, Harhay MO, Klein MJ, Shein SL, Pineres-Olave BE, Izquierdo L, Sapru A, Emeriaud G, Spinella PC, Flori HR, et al. Predicting mortality in children with pediatric acute respiratory distress syndrome: a pediatric acute respiratory distress syndrome incidence and epidemiology study. Crit Care Med. 2020;48(6):e514-22.

33. Calfee CS, Janz DR, Bernard GR, May AK, Kangelaris KN, Matthay MA, Ware LB. Distinct molecular phenotypes of direct vs indirect ARDS in singlecenter and multicenter studies. Chest. 2015;147(6):1539-48.

34. Willson DF, Truwit JD, Conaway MR, Traul CS, Egan EE. The adult calfactant in acute respiratory distress syndrome trial. Chest. 2015;148(2):356-64.

35. Luo L, Shaver CM, Zhao Z, Koyama T, Calfee CS, Bastarache JA, Ware LB. Clinical predictors of hospital mortality differ between direct and indirect ARDS. Chest. 2017;151(4):755-63.

36. National Heart L, Blood Institute ACTN, Truwit JD, Bernard GR, Steingrub J, Matthay MA, Liu KD, Albertson TE, Brower RG, Shanholtz C, et al. Rosuvastatin for sepsis-associated acute respiratory distress syndrome. N Engl J Med. 2014;370(23):2191-200.

37. Yehya N, Keim G, Thomas NJ. Subtypes of pediatric acute respiratory distress syndrome have different predictors of mortality. Intensive Care Med. 2018;44(8):1230-9.

38. Mrozek S, Jabaudon M, Jaber S, Paugam-Burtz C, Lefrant JY, Rouby $\mathrm{J}$, Asehnoune K, Allaouchiche B, Baldesi O, Leone M, et al. Elevated plasma levels of sRAGE are associated with nonfocal CT-based lung imaging in patients with ARDS: a prospective multicenter study. Chest. 2016;150(5):998-1007.

39. Constantin JM, Jabaudon M, Lefrant JY, Jaber S, Quenot JP, Langeron O, Ferrandiere M, Grelon F, Seguin P, Ichai C, et al. Personalised mechanical ventilation tailored to lung morphology versus low positive endexpiratory pressure for patients with acute respiratory distress syndrome in France (the LIVE study): a multicentre, single-blind, randomised controlled trial. Lancet Respir Med. 2019;7(10):870-80.

40. Bos LDJ, Scicluna BP, Ong DSY, Cremer O, van der Poll T, Schultz MJ. Understanding heterogeneity in biologic phenotypes of acute respiratory distress syndrome by leukocyte expression profiles. Am J Respir Crit Care Med. 2019;200(1):42-50.

41. Jodele S, Dandoy CE, Lane A, Laskin BL, Teusink-Cross A, Myers KC, Wallace G, Nelson A, Bleesing J, Chima RS, et al. Complement blockade for TA-TMA: lessons learned from a large pediatric cohort treated with eculizumab. Blood. 2020;135(13):1049-57.

42. Ware LB, Matthay MA. The acute respiratory distress syndrome. N Engl J Med. 2000;342(18):1334-49.

43. Matthay MA, Ware LB, Zimmerman GA. The acute respiratory distress syndrome. J Clin Investig. 2012;122(8):2731-40

44. Muir R, Osbourn M, Dubois AV, Doran E, Small DM, Monahan A, O'Kane CM, MCAllister K, Fitzgerald DC, Kissenpfennig A, et al. Innate lymphoid cells are the predominant source of IL-17A during the early pathogenesis of acute respiratory distress syndrome. Am J Respir Crit Care Med. 2016;193(4):407-16.

45. Yu ZX, Ji MS, Yan J, Cai Y, Liu J, Yang HF, Li Y, Jin ZC, Zheng JX. The ratio of Th17/Treg cells as a risk indicator in early acute respiratory distress syndrome. Crit Care. 2015;19:82.

46. Krjutskov K, Koel M, Roost AM, Katayama S, Einarsdottir E, Jouhilahti EM, Soderhall C, Jaakma U, Plaas M, Vesterlund L, et al. Globin mRNA reduction for whole-blood transcriptome sequencing. Sci Rep. 2016;6:31584.

47. Choi I, Bao H, Kommadath A, Hosseini A, Sun X, Meng Y, Stothard P, Plastow GS, Tuggle CK, Reecy JM, et al. Increasing gene discovery and coverage using RNA-seq of globin RNA reduced porcine blood samples. BMC Genom. 2014;15:954

48. Wong HR, Cvijanovich NZ, Allen GL, Thomas NJ, Freishtat RJ, Anas N, Meyer K, Checchia PA, Lin R, Shanley TP, et al. Validation of a gene expression-based subclassification strategy for pediatric septic shock. Crit Care Med. 2011;39(11):2511-7.

49. Flori HR, Glidden DV, Rutherford GW, Matthay MA. Pediatric acute lung injury: prospective evaluation of risk factors associated with mortality. Am J Respir Crit Care Med. 2005;171(9):995-1001.

50. Erickson S, Schibler A, Numa A, Nuthall G, Yung M, Pascoe E, Wilkins $B$. Acute lung injury in pediatric intensive care in Australia and New Zealand: a prospective, multicenter, observational study. Pediatr Crit Care Med. 2007:8(4):317-23.

51. Parvathaneni K, Belani S, Leung D, Newth CJ, Khemani RG. Evaluating the performance of the pediatric acute lung injury consensus conference definition of acute respiratory distress syndrome. Pediatr Crit Care Med. 2017;18(1):17-25

52. Pediatric Acute Lung Injury Consensus Conference Group. Pediatric acute respiratory distress syndrome: consensus recommendations from the Pediatric Acute Lung Injury Consensus Conference. Pediatr Crit Care Med. 2015;16(5):428-39.

\section{Publisher's Note}

Springer Nature remains neutral with regard to jurisdictional claims in published maps and institutional affiliations.
Ready to submit your research? Choose BMC and benefit from:

- fast, convenient online submission

- thorough peer review by experienced researchers in your field

- rapid publication on acceptance

- support for research data, including large and complex data types

- gold Open Access which fosters wider collaboration and increased citations

- maximum visibility for your research: over 100M website views per year

At BMC, research is always in progress.

Learn more biomedcentral.com/submissions 